\title{
Community
}

\section{News from the European Optical Society (EOS)}

DOI 10.1515/aot-2017-0026

\section{EOS Optical Technologies}

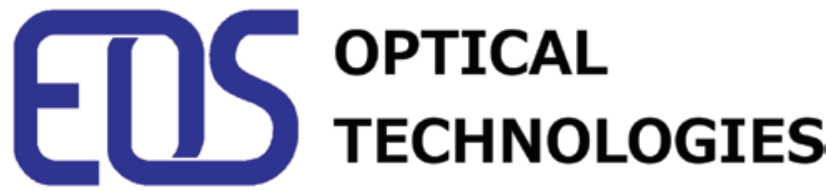

Munich, Germany, June 26-29, 2017

The European Optical Society (EOS) conferences as part of the World of Photonics Congress in Munich will be held for the first time under one title: EOS Optical Technologies.

Register: www.conftool.com/wpc2017

Conference Program: www.conftool.com/wpc2017

These conferences include:

- Manufacturing of Optical Systems (Monday 26 Wednesday 28, June)

- $\quad$ Light Engineering (Monday 26 - Tuesday 27, June)

- Optofluidics (Wednesday 28 - Thursday 29, June)

- Optomechanical Engineering (Merged into Manufacturing of Optical Systems)

For the first time, an industrial poster session will be held within the Manufacturing of Optical Systems Conference. Attendees will have a chance to view the posters during the sessions and during breaks as the posters will be visible in the conference room.

\section{EOS Annual General Assembly}

The EOS Annual General Assembly for all EOS members will be held during the congress on Wednesday, June 28,
2017, at the ICM convention center in Munich. A separate invitation has been sent to all members.

Register and make use of your EOS membership to get reductions on conference fees: www.conftool.com/ wpc2017

To join EOS and receive considerable discounts, go to our Online Shop: https://shop.myeos.org/index.php (Individual membership €50, students €10)

By registering with EOS you get admission to all conferences held at the World of Photonics, as well as entrance free of charge to the leading international LASER World of PHOTONICS fair. Please note that the registration through EOS guarantees your access to all these conferences but does not necessarily entitle you to some specificities of each conference, such as proceedings, dinners, etc. Please check this beforehand at: http://www.photonicscongress.com

EOS Conferences are held under the umbrella of the World of Photonics Congress 2017, the leading international congress for optical technologies in Europe (June 25-29, 2017).

More about the congress: http://www.myeos.org/ events/WPC2017

See you in Munich, June 26-29, 2017!

\section{EOS Topical Meeting on Diffractive Optics 2017 (D02017)}

Joensuu, Finland, September 4-7, 2017

Register: www.conftool.com/do2017

Early Bird until July 3, 2017.

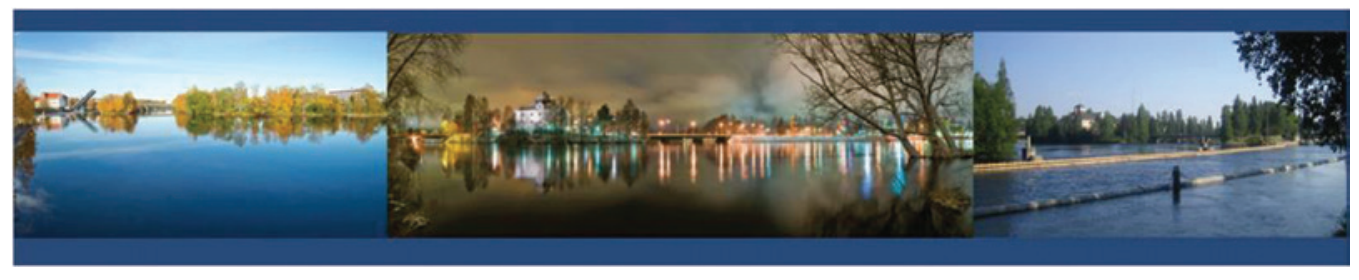

www.degruyter.com/aot

(c) 2017 THOSS Media and De Gruyter 
This topical meeting series on Diffractive Optics was established in 1995, with the inaugural meeting in Prague. The series continued on a biennial basis with meetings held all over Europe. Diffractive Optics first came to Savonlinna in 1997. Chaired again by professors Jari Turunen, and Frank Wyrowski, joined by Prof. Tero Setälä, this year makes an important 20-year milestone for the meeting. In 2014 and 2016, the Diffractive Optics meeting was arranged as a part of the European Optical Society biennial Meeting (EOSAM). A decision was made by the EOS to re-establish Diffractive Optics as an independent EOS Topical Meeting, once again to be held biennially.

The scope of the meeting covers all fundamental and applied aspects of diffractive optics and related fields. The topical meeting will once again be an informal, workshop-like gathering of like-minded people, respecting the old traditions but also expanding the scope according to recent developments in the field. The meeting will be held in Joensuu, Finland, a part of the Lake District and Region of North Karelia. The venue is situated on an island in the middle of the Joensuu city with beautiful scenery.

Collocated with the topical meeting, an exhibition will be held, where companies are entitled to present their products and know-how to the attendees. For available exhibition spaces, companies should contact the organizers, do2017@myeos.org.

A workshop on Fast Physical Optics Modeling with VirtualLab Fusion Software will be held on Thursday evening, September 7, after the conference. The workshop is led by Prof. Frank Wyrowski. In the workshop, the theoretical foundations of second-generation field tracing are presented and illustrated with examples in VirtualLab Fusion. Examples include lens systems with gratings and diffractive lenses, systems with etalons, crystals, gradedindex media and waveguide plates for virtual-and mixedreality applications.

For more information on the topical meeting, please visit: www.myeos.org/events/do2017 